\title{
Message from the President of BSCCM
}

The publication of the first issue of Bangladesh Critical Care Journal (BCCJ) is a great milestone in the history of Critical Care Medicine of Bangladesh. The recognition of Critical Care Medicine (CCM) as a primary care specialty came first time in 1996 with the establishment of department of Critical Care Medicine at Intensive Care Unit (ICU) of BIRDEM General Hospital. Concept of establishment of CCM as an independent department did not gain much ground till now in spite of rapid growth in number of ICUs across the country during last several years. In 2007 CCM as a postgraduate specialty was approved by Ministry of Health, Government of Bangladesh and University of Dhaka.

Later Bangabandhu Sheikh Mujib Medical University (BSMMU) accepted CCM as one of its postgraduate courses and has been conducting post graduation examinations regularly. The first postgraduate course in CCM began in BIRDEM General Hospital in 2008 and Dhaka Medical College Hospital received approval to admit students in this course in its department of Anaesthesia in 2009. In 2012, Bangladesh Medical and Dental Council gave approval to the MD CCM program of BIRDEM General Hospital.

The first international conference on Critical Care Medicine entitled "Criticon Bangladesh 2013" along with preconference workshops has been set for launch on 14-17 March 2013. This is going to be another significant milestone in the evolution of BSCCM. On the occasion of this landmark conference BSCCM has embarked on bringing out the inaugural issue of Bangladesh Critical Care Journal. This journal is expected to serve as a platform for research and scientific development of our medical community in the field of Critical Care Medicine. This inaugural issue contains several original papers, review articles and case reports of great educational value for our physicians. We plan on transforming the journal into a peer reviewed indexed journal currently to be published biannually. We envision to bring it up to be a prestigious internationally recognized journal in years to come.

My heartfelt congratulations go to the editorial team led by Dr. ARM Nooruzzaman (scientific secretary of BSCCM and executive editor BCCJ) and team members composed of Dr. A. S. M. Areef Ahsan (organizing secretary of BSCCM and member of editorial board of BCCJ), Dr. Asif Mujtaba Mahmud (Secretary of Inter society affairs of BSCCM and member of editorial board of BCCJ) and Dr. Raihan Rabbani (Publication Secretary of BSCCM and member of editorial board, $\mathrm{BCCJ}$ ) for their tireless effort in publishing this issue.

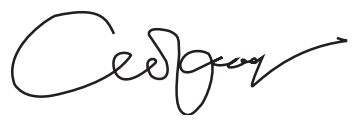

\section{Professor Mohammad Omar Faruq}

President, BSCCM

Chief Editor, Bangladesh Critical Care Journal 